\title{
Cognitive Styles of Adolescent Students in Relation to their Stress Level
}

\author{
Dr. Rajat Kumar Jain ${ }^{1}$, Manisha Verma ${ }^{2}$, Hemant Kumar Jain ${ }^{3}$ \\ ${ }^{1}$ Reader in Education, Shri Shankaracharya Mahavidyalya, Junwani, Bhilai, (Chhattisgarh) \\ ${ }^{2}$ Research Scholar \\ ${ }^{3}$ Assistant Professor, Shri Rawatpura Sarkar, Department of Education, Kumhari, Raipur (Chhattisgarh)
}

\begin{abstract}
Present study was conducted to find out the impact of stress on cognitive styles of adolescent students. Stress is the sensation of being overwhelmed by responsibilities or pressure. As a psychological concept, stress was first introduced in the 1950's, with the term originally taken from physics, where it described the amount of tension placed upon an object. Cognition is acquisition of knowledge which involves a series of mental skills. Style of thinking is used in cognitive psychology to describe the way an individual thinking, perceive and remember information or their preferred recurring pattern of perceptual and intellectual society. Also, culture provides people with a range of a cognitive style that are appropriate for different cognitive task in different context. The study was conducted on 100 undergraduate students from studying in different colleges located in Bhilai (Chhattisgarh). It can be concluded that, there was no significant impact of stress on cognitive style of college going male student.But significant impact of stress on cognitive styles was found on of female undergraduate students.
\end{abstract}

Keywords: Cognitive Style; Stress; College going Student; Systemic Style; Intuitive Style; Adolescent

\section{Introduction}

Stress is the part of our life and it beautifully plays its role in our life. Although we feel it is harmful for our life but there is no doubt it is a good motivator too. Stress is the sensation of being overwhelmed by responsibilities or pressure. As a psychological concept, stress was first introduced in the 1950 's, with the term originally taken from physics, where it described the amount of tension placed upon an object.

The important part of the stress definition is feeling overwhelmed (Scott Colter (2015). Many people have huge levels of responsibility but nonetheless thrive in difficult or taxing situations. Stress is the distinct feeling of being pushed or pulled too thin and it doesn't directly correlate to the level of responsibility that you may have, although responsibility and pressure are often factors. Stress has a wide range of symptoms. It is a well known fact that it can increase blood pressure and heart beat rate, affecting sleeping patterns, produces a loss of appetite disturbs concentration and contributes to a wide range of mental illnesses, such as depression.

Now the question arise what exactly stress is? There are many definitions and even researchers in this field use the term in several ways. To some psychologists, stress is an event that produces tension or worry. Others describe it as a person's physical or psychological response to such an event. Still other researchers regard stress as a person's perception of the event. Simply we can say that Stress is the anxious or threatening feeling resulting from our appraisal of a situation and our reaction to demands placed upon us. As Baron (1992) say "Stress is many- faceted process that occurs in us in response to events that disrupt or threaten to disrupt our physical or psychological functioning."

Cognitive style a usually described as a personality dimension which influences attitudes, values and social interaction. It also describes how the individual acquires knowledge (cognition) and how an individual processes information (conceptualization). Cognitive style has been viewed from different angles. Goldstein and Blackman (1978) define cognitive style as a hypothetical construct that has been developed to explain the process of mediation between stimuli and responses. Here the term cognitive style refers to the characteristic way in which individuals conceptually organize the environment. It is also related to mental behaviors, habitually applied by an individual to problem solving, and generally to the way that information is obtained, sorted and utilized.

\section{Literature Review-}

1. Saxena, Jain \& Jain (2014) conducted a study to find out the impact of cognitive style on problem solving ability among undergraduates and they find out the impact of cognitive style on problem solving ability of undergraduate students. They conclude that, there was no significant impact of cognitive style on problem solving ability of undergraduate student of integrated and split style. Similarly no significant impact of cognitive style on problem solving ability of male undergraduate students of integrated and split style. The significant difference was found in the problem solving ability of females of integrated and split style. A significant difference was also accounted in the problem solving ability of science and non science students. Discipline of study has a major role in determining the degree of problem solving ability.

2. Mark and Richard (2011) have made a study to investigate the relationship between the teacher's cognitive style and occupational stress. A sample of 212 teachers in Maltese secondary schools completed a questionnaire surveying both the level of overall stress and the severity of four major areas of job stress. They have found significant variations in the level of stress with observed style. 


\section{International Journal of Science and Research (IJSR) \\ ISSN (Online): 2319-7064}

Index Copernicus Value (2015): 78.96 | Impact Factor (2015): 6.391

Analytics reported greater stress than Who lists for 'pupil misbehavior' and 'poor working conditions', the converse was true for 'poor staff relations' and 'time pressures'

3. Melinda, Luzelle, et al. (2014) has made a study to determine whether black South African adolescents with different cognitive styles (i.e. rational or experiential) differ in their levels of stress and coping. Furthermore, the common stressors that black adolescents experience and the coping styles predominantly used by black adolescents could be determined. They found that Adolescents operating from an experiential cognitive style experienced more stress regarding school performance, school attendance, financial pressure and emerging adult responsibility than adolescents operating from a rational cognitive style. Adolescents employing a rational style sought more alternative rewards as a coping strategy, whereas adolescents employing an experiential style relied more on emotional discharge.

4. Reinking, \&Goldstein (2016 ) In a research study from 181 female undergraduates indicated that (a) performance on the rod-and-frame test (RFT) in a condition in which Ss took the test in a tilted position was more adversely affected for field-dependent than field-independent Ss; (b) inducing a set in Ss to focus on internal cues while performing the RFT led to better performance than inducing a set to focus on external cues; and (c) under stress, performance on the RFT for field-dependent Ss appeared more extremely field dependent than in the absence of stress, and under stress, performance on the RFT for field-independent Ss appeared more extremely field independent than in the absence of stress.

5. Salam, Raynuha et al. (2015). Identify the stressprevalence and coping-strategies among University Kebangsaan Malaysia (UKM) medical students. They found that overall stress-prevalence was 49\%. Female and Malay respondents were more stressed. Significant differences of stress-level was observed between Malays and non Malays in first year $(p=0.04)$ and in third year $(p=0.01)$. Most common strategies used to cope stress were task-oriented while emotion oriented was least. Stress-prevalence and stress-level in UKM medical students was high. Most of the respondents coped stress using task-oriented strategies. Stressor and its effective management must be ensured. Educational institutions should act as a creative designer of learning environment to get relieve from educational stressor.

We haven't found any study related to our topic. Hence we decided to choose this topic for research purpose.

\section{Objective}

1. To study the impact of stress on cognitive styles of adolescent students.

\section{Hypothesis -}

H1- There exists no significant difference in the systematic cognitive style of male adolescent students with high and low stress level.

H2- There exist no significant difference in the intuitive cognitive style of adolescent (male students) with high and low stress level.
H3- There exist no significant difference in the systematic cognitive style of adolescent (female students) with high and low stress level.

H4- There exist no significant difference in the intuitive cognitive style of adolescent (female students) with high and low stress level.

\section{Sample}

For the present study a total of 200 graduate students (100 Male and 100Female) were selected for the study by adopting random sampling method from various colleges of Bhilai Nagar.

\section{Tools}

In the present study, Students Stress Scale was used to measure the Students Stress by Dr. Zaki Akhtar. Whereas Students Cognitive Style was measured by Cognitive Style Inventory constructed by Praveen Kumar Jha.

\section{Analysis and Discussion}

To test the hypotheses data was collected accordingly and scoring was done as per the procedure stated in the manuals. According to the scores obtained by the cognitive style inventory all the students were categorized into different cognitive styles. Since a less number of students fall in undifferentiated, integrated and split, they were not taken for further studies. Statistical analysis was employed on the scores obtained from subject of systematic and intuitive of cognitive style.

To find out the impact of stress on cognitive styles ability ' $t$ ' test was employed and findings are as follows.

Table 1: Table Showing Mean, Standard Deviation and't' Value of systematic cognitive style of male adolescent students with high and low stress level

\begin{tabular}{|c|c|c|c|c|c|}
\hline S. No & Groups & $\mathrm{N}$ & $\mathrm{M}$ & $\sigma$ & $\mathrm{t}-$ Value \\
\hline 1. & Students with high stress & 50 & 76.86 & 9.441 & 0.780 \\
\cline { 1 - 4 } 2. & Students with Low stress & 50 & 78.68 & 13.32 & \\
\hline \multicolumn{6}{|c|}{ df $=98, \mathrm{p}>0.05$, Non significant } \\
\hline
\end{tabular}

Table 1 shows that calculated ' $\mathrm{t}$ ' value for systematic cognitive style scores of high and low stress level male adolescent student is less than table value at .05 level of significance. Hence hypothesis is accepted. It indicates that there is no significant difference between the systematic cognitive styles of high and low stress level male adolescent.

Table 2: Table Showing Mean, Standard Deviation and't' Value of intuitive cognitive style of adolescent (male students) with high and low stress level.

\begin{tabular}{|c|c|c|c|c|c|}
\hline S. No & Groups & $\mathrm{N}$ & $\mathrm{M}$ & $\sigma$ & $\mathrm{t}-$ Value \\
\hline 1. & Students with high stress & 50 & 70.9 & 9.72 & 1.33 \\
\hline 2. & Students with Low stress & 50 & 67.08 & 12.45 & \\
\hline \multicolumn{4}{|c|}{ df $=\mathbf{9 8}, \mathbf{p}>\mathbf{0 . 0 5}$, Non significant } \\
\hline
\end{tabular}

Table 2 shows that calculated ' $t$ ' value for intuitive cognitive style scores of high and low stress level male adolescent student is less than table value at .05 level of significance. Hence hypothesis is accepted. It indicates that there is no significant difference between the systematic cognitive styles of high and low stress level male adolescent. 


\section{International Journal of Science and Research (IJSR) \\ ISSN (Online): 2319-7064}

Index Copernicus Value (2015): 78.96 | Impact Factor (2015): 6.391

Table 3: Table Showing Mean, Standard Deviation and ' $t$ ' Value of systematic cognitive style of adolescent (female students) with high and low stress level

\begin{tabular}{|c|c|c|c|c|c|}
\hline S. No & Groups & $\mathrm{N}$ & $\mathrm{M}$ & $\sigma$ & $\mathrm{t}$ - Value \\
\hline 1. & Students with high stress & 50 & 44.82 & 56.67 & \multirow{2}{*}{$\mathbf{2 . 0 0 3}$} \\
\cline { 1 - 5 } 2. & Students with Low stress & 50 & 39.90 & 74.14 & \\
\hline \multicolumn{4}{|c|}{ df $=\mathbf{9 8 , \mathbf { p } < \mathbf { 0 . 0 5 } , \text { Significant }}$} \\
\hline
\end{tabular}

Table 3 shows that calculated ' $t$ ' value for systematic cognitive style scores of high and low stress level female adolescent student is high than table value at .05 level of significance. Hence hypothesis is rejected. It indicates that there is significant difference between the systematic cognitive styles of high and low stress level female adolescent.

Table 4: Table Showing Mean, Standard Deviation and ' $t$ ' Value of intuitive cognitive style of adolescent (female students) with high and low stress level

\begin{tabular}{|c|c|c|c|c|c|}
\hline S. No & Groups & $\mathrm{N}$ & M & $\sigma$ & $\mathrm{t}$-Value \\
\hline 1. & Students with high stress & 50 & 43.15 & 70.28 & \multirow[t]{2}{*}{1.984} \\
\hline 2. & Students with Low stress & 50 & 39.18 & 70.36 & \\
\hline \\
\hline
\end{tabular}

Table 4 shows that calculated't' value for intuitive cognitive style scores of high and low stress level female adolescent student is high than table value at .05 level of significance. Hence hypothesis is rejected. It indicates that there is significant difference between the systematic cognitive styles of high and low stress level female adolescent.

\section{Conclusions}

It can be concluded from the study that stress level has no impact on systematic and intuitive cognitive style of undergraduate .In case of male undergraduate; stress level also does not play any significant role in - cognitive style. But in female undergraduates it plays a significant role upon cognitive styles. Significant difference was found on the systemic and intuitive cognitive style of female undergraduates. We can say perhaps males can manage stress level compared to female. On the basis of result of the data we can see that stress level on female makes significant effect on systematic and intuitive cognitive styles. This happens perhaps due to the more sensitive nature of the female. We can observe the effect of this nature on their cognitive style clearly.

\section{References}

[1] Colter, Scott, CONQUER THE BATTLES OF YOUR MIND WITHPOWERFUL TECHNIQUES TO OVERCOME STRESS, ANXIETY \& NEGATIVE THINKING, Invicta House Publishing, 2015.

[2] Baron, Robert A. Stress; cause and effects and control, Psychology, Prentice Hall of India private limited, 2006, p 494.

[3] Goldstein, K.M, Blackman, S. Cognitive Styles: Five Approaches and Relevant Research. New York: Wiley \& Sons, 1978.

[4] Saxena, Sumanlata, Jain, Rajat Kumar \& Jain, Hemant Kumar et al. IMPACT OF COGNITIVE STYLE ON PROBLEM SOLVING ABILITY AMONG UNDER -
GRADUATES, International Journal of Human Resource Management and Research (Ijhrmr), Vol. 4, Issue 2, Apr 2014, PP 59-64.

[5] Mark, G. Borg \& Richard, J. Riding. The British Psychological Society British Journal of Educational Psychology, Volume 63, Issue 2, 2011, pages 271-286.

[6] Rooyen, Melinda van; Naude, Luzelle; et.al. Journal of Mental Health, vol-23,issue-6 2014, Pages 340.

[7] Reinking, Richard; Goldstein, Gerald et al. Cognitive style, proprioceptive skills, task set, stress, and the Rodand-Frame Test of field orientation. Journal of Personality and Social Psychology, 2016, Vol. 30 (6).

[8] Salam, Abdus, Mahadevan Raynuha et al. To identify the stress-prevalence and coping- strategies among University Kebangsaan Malaysia (UKM) medical students. Pak J Med Sci., Jan-Feb (2015), 31(1), 169173.

[9] Jackson, Sherri L. Research Methods and Statistics, CENGAGE Learning, 2009. 